\title{
Flea infestation reduces the life span of the common vole
}

\author{
G. DEVEVEY ${ }^{1,2 *}$ and P. CHRISTE ${ }^{1}$ \\ ${ }^{1}$ Department of Ecology $\&$ Evolution, University of Lausanne, Biophore, CH-1015 Lausanne, Switzerland \\ ${ }^{2}$ Department of Biology, University of Pennsylvania, 433 S. University Avenue, Philadelphia PA 19104, USA
}

(Received 31 March 2009; revised 14 May and 2 Fune 2009; accepted 15 Fune 2009; first published online 7 August 2009)

\begin{abstract}
SUMMARY
Parasitism is often a source of variation in host's fitness components. Understanding and estimating its relative importance for fitness components of hosts is fundamental from physiological, ecological and evolutionary perspectives. Host-parasite studies have often reported parasite-induced reduction of host fecundity, whereas the effect of parasitism on host survival has been largely neglected. Here, we experimentally investigated the effect of infestation by rat fleas (Nosopsyllus fasciatus) on the life span of wild-derived male common voles (Microtus arvalis) bred in captivity. We found that the mean life span of parasitized voles was reduced by $36 \%$ compared to control voles. Parasitized voles had a smaller body size, but a relatively larger heart and spleen than control voles. These results indicate an effect of flea infestation on host life span and our findings strongly suggest that ectoparasites should be taken into account in the studies of host population dynamics.
\end{abstract}

Key words: life-history traits, Microtus arvalis, Nosopsyllus fasciatus, parasitism, survival.

\section{INTRODUCTION}

Parasites are often assumed to affect the host's lifehistory traits in a way that depresses the host's fitness (Møller, 1997). Any depression of the host's fitness occurs through a reduction of the number of reproductive attempts (estimated by the life span and time to first reproduction) and/or a reduction of the fecundity (i.e. the number of produced offspring per reproductive attempt) (Stearns, 1992). Thus parasitism can ultimately result in strong effects on host population dynamics, as suggested by empirical and theoretical studies (Anderson and May, 1978; Dobson and Hudson, 1992; Hudson et al. 1992, 1998). Reduction of fecundity due to ectoparasitism has been documented several times (e.g. Deter et al. 2007; Møller, 1997; Neuhaus, 2003; Saino et al. 1998), whereas evidence of the negative effect of ectoparasites on life span and thus on the reproductive life-time is scarce (but see Brown et al. 1995).

Among host-parasite interactions, small mammals and their ectoparasites have been understudied despite their ecological importance in terrestrial ecosystems and their role in epidemiology of several zoonoses (e.g. Chagas' disease: Garcia et al. 2007, Lyme disease: Brisson et al. 2008). Fleas are widespread parasites of small mammals, vectors of numerous diseases (Medvedev and Krasnov, 2006) and their effects on host's fitness are largely unknown. Some recent studies in gerbils demonstrated that

* Corresponding author: Department of Ecology \& Evolution, University of Lausanne, Biophore, CH-1015 Lausanne, Switzerland. Tel: +1215 746 1732. Fax: +1215898 8780. E-mail: godefroy.devevey@unil.ch fleas induce body mass loss in adult desert gerbils Gerbillus dasyurus (Khokhlova et al. 2002), whereas this was not the case in adult Anderson's gerbils Gerbillus andersoni (Hawlena et al. 2006a). Flea infestation may also reduce immune defences (Goüy de Bellocq et al. 2006; Devevey et al. 2008), which in turn may affect survival. However, evidence of reduced recapture rate has only been provided in parasitized juvenile Anderson's gerbils (Hawlena et al. 2006 b). In the common vole Microtus arvalis, flea infestation affects growth and body mass, depresses host immune defences and induces anaemia (Devevey et al. 2008), which could severely reduce survival probability, but definitive tests of the effect of flea infestation on life span are still lacking.

In this study, we experimentally tested whether parasitism by fleas reduces the life span of their hosts, the common vole. We monitored the life span of captive males parasitized by fleas or kept noninfested until natural death. We also measured haematocrit and body condition throughout life, and at death we weighed spleen, heart, and testes in order to examine whether life span variations could be due to physiological disorders.

\section{MATERIALS AND METHODS}

The stock population consisted of wild adult common voles from meadows surrounding the University of Lausanne (Switzerland). Voles were deparasitized with $4 \mu \mathrm{l}$ of $120 \mathrm{mg} / \mathrm{ml}$ veterinary selamectin (Stronghold®), Pfizer, New-York) deposited beneath the ear at their arrival in the animal room. Topical application of selamectin provides effective 
protection against external and internal parasites during 4 weeks without negative side-effects on host health (Pipano, 2003). Experimental animals were male common voles born from the stock population. They were aged between 45 and 60 days at the start of the experiment (day 0). Common voles reach their adult size at 3 months (Jacob, 2003). All animals were individually housed in a polypropylene cage $(36 \mathrm{~cm} \times 20 \mathrm{~cm} \times 18 \mathrm{~cm})$ in an animal room with a 14 $\mathrm{L}: 10 \mathrm{D}$ cycle and constant temperature of $21 \pm 1{ }^{\circ} \mathrm{C}$. Cages contained 1 litre of sterilized soil and a flowerpot (diameter $14 \mathrm{~cm}$ ) as a vole roost. Hay and tap water were available ad libitum and animals received apples and seeds regularly throughout the experiment.

At day 0, 52 adult males originating from 25 litters were weighed, measured, and blood sampled. At day 1 , individuals were randomly assigned to the fleatreatment group or non-parasitized control group. Twenty eight individuals were parasitized by fleas (treatment group) and 24 individuals were kept as control. Parasitized voles were exposed to adult and larval rat flea Nosopsyllus fasciatus by receiving $15 \mathrm{~g}$ of a mix of bedding coming from cages of wild voles which were not deparasitized and where fleas had developed naturally. In 4 samples of $15 \mathrm{~g}$ of bedding, flea loads comprised between 25 and 64 individuals (average $=44$ fleas). The control group received $15 \mathrm{~g}$ of a mix of bedding without fleas. Voles were housed in the same animal facility and the cages were randomly placed on shelves. See Devevey et al. (2008) for more details.

Body mass and haematocrit were measured at the start of the experiment and at days 98, 119, 139, 237, $335,430,640$, and 742 . Sample sizes decrease over time due to this design running until the natural death of every individual.

On each blood sampling day, blood was drawn by tail-cutting into a pre-heparinized capillary for haematocrit. Haematocrit capillaries were centrifuged for $10 \mathrm{~min}$ with a standard centrifuge (Haematokrit 24, Bioréac SA, Lausanne, Switzerland). The amount of red blood cells relative to the total amount of blood volume was measured with a calliper to the nearest $0.1 \mathrm{~mm}$. Body mass was measured to the nearest $0 \cdot 1 \mathrm{~g}$. After death, corpse length from the tip of the nose to the base of the tail was measured on a graduated board. Individual body condition at day 98 and the following days was assessed by extracting residuals from the regression of body mass on body length $\left(\mathrm{r}^{2}=0 \cdot 11, n=174, P<0 \cdot 001\right)$. Then the heart, spleen and testes were removed, cleaned from connective tissue and weighed $(0 \cdot 1 \mathrm{mg})$.

Effect of parasitism on life span of voles was first tested by a Kaplan-Meier survival analysis. The Kaplan-Meier estimator is a product-limit survival estimate from life-time data (Kaplan and Meier, 1958). We analysed change in haematocrit and body condition throughout adulthood (age equal or older

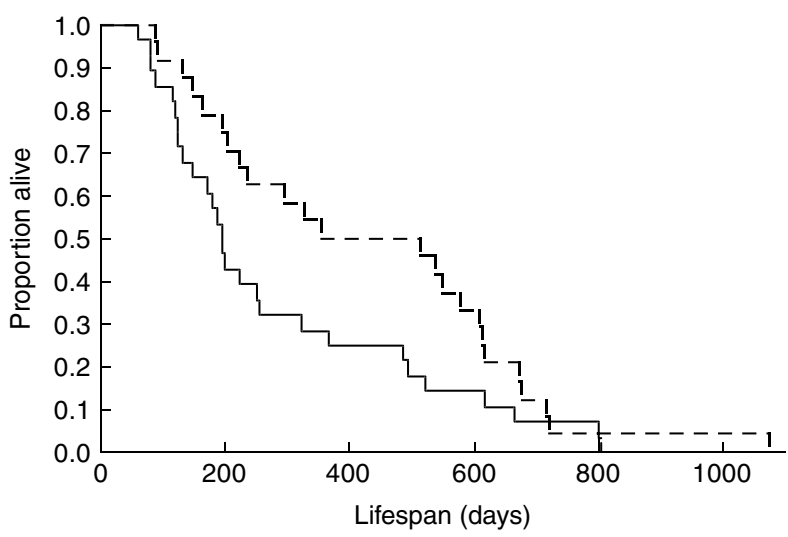

Fig. 1. Life span curves of voles infested by fleas (full line) or non-infested by fleas (dashed line).

than 98 days) with repeated-measure ANOVA over continuous time in backward procedure. Because changes in haematocrit or body condition over time can be due to within-individual changes (improvement, senescence) or to between-individual change (selective disappearance), we added the factor 'age of last measurement' in the ANOVA (van de Pol and Verhulst, 2006). To control for allometric relationships between corpse mass and organs (heart: $\mathrm{R}^{2}=0 \cdot 45, \mathrm{~F}_{1,26}=20 \cdot 9, P<0 \cdot 001$; spleen: $\mathrm{R}^{2}=0 \cdot 06$, $\mathrm{F}_{1,25}=1 \cdot 6, \quad P=0 \cdot 2$; testes: $\mathrm{R}^{2}=0 \cdot 49, \quad \mathrm{~F}_{1,29}=28 \cdot 1$, $P<0 \cdot 001$ ), we entered corpse mass as a covariate in the analyses of the mass of spleen, heart and testes. Variables were log-transformed if necessary in order to normalise the distribution. Reported values are means \pm standard error. All tests were two-tailed and were performed with JMP 7.0.0.

\section{RESULTS}

The life span of parasitized voles (mean: 293.7 days, median: 194 days, max: 804 days) was reduced compared to control voles (mean: 460 days, median: 538 days, $\max : 1076$ days; $\chi^{2}=6 \cdot 04, \quad$ D.F. $=1$, $P=0 \cdot 014$; Fig. 1), even after excluding voles which did not reach 100 days of age (respective medians, 224 and 550 days; $\chi^{2}=6 \cdot 07$, D.F. $\left.=1, P=0 \cdot 014\right)$.

The two groups did not differ for body mass and haematocrit at the start of the experiment ( $t$-tests, respectively $t_{49}=0 \cdot 32, P=0.8$ and $\left.t_{49}=0 \cdot 61, P=0 \cdot 5\right)$. The mean haematocrit level of parasitized voles $(0 \cdot 43 \pm 0 \cdot 00)$ was lower than in control voles $(0.52 \pm 0.00)$ throughout life, and in both groups the level decreased as voles aged (Table 1). Body condition tended to be lower in parasitized voles than controls and diminished with age in non-parasitized individuals $\left(\mathrm{F}_{1,98}=9 \cdot 75, \quad P=0.002 ;\right.$ Table 1), whereas that was not the case in parasitized voles $\left(\mathrm{F}_{1,72}=0.53, P=0 \cdot 47\right)$. The non-significant term 'age of last measurement' means that the changes are due to individual variation of trait values and not to selective disappearance (van der Pol and Verhulst, 2006). 
Table 1. Results of the repeated measures analyses of variance on haematocrit and body condition throughout the life-time of voles

(The mean haematocrit level of parasitized voles was lower than in control voles, and in both groups the level decreased as voles aged. Body condition tended to be lower in parasitized voles than controls and diminished with age in non-parasitized individuals, whereas that was not the case in parasitized voles.)

\begin{tabular}{|c|c|c|c|}
\hline Factors & D.F. & $\mathrm{F}$ & $P$ \\
\hline \multicolumn{4}{|l|}{ Haematocrit } \\
\hline Age & $1,142 \cdot 6$ & 11.98 & $<0.001$ \\
\hline Parasitism & $1,33 \cdot 6$ & $123 \cdot 18$ & $<0.001$ \\
\hline $\begin{array}{l}\text { Age at last } \\
\text { measurement }\end{array}$ & $1,144 \cdot 5$ & $0 \cdot 51$ & $0 \cdot 48$ \\
\hline \multicolumn{4}{|l|}{ Body condition } \\
\hline Age & $1,135 \cdot 7$ & $1 \cdot 22$ & $0 \cdot 27$ \\
\hline Parasitism & $1,33 \cdot 1$ & $3 \cdot 95$ & $0 \cdot 055$ \\
\hline $\begin{array}{l}\text { Age at last } \\
\text { measurement }\end{array}$ & $1,168 \cdot 9$ & $1 \cdot 41$ & $0 \cdot 24$ \\
\hline Age $\times$ Parasitism & $1,146 \cdot 6$ & $7 \cdot 13$ & $0 \cdot 008$ \\
\hline
\end{tabular}

At the time of death, parasitized voles were smaller than those of non-parasitized voles (respectively $101 \cdot 7 \pm 2 \cdot 2 \mathrm{~mm}$ and $111.9 \pm 2.2 \mathrm{~mm}, \quad t_{34}=3 \cdot 24$, $P=0.003)$. After controlling for body mass, parasitized voles had larger spleens (non-parasitized: $31 \cdot 8 \mathrm{mg} \pm 1 \cdot 3$; parasitized : $87 \cdot 4 \mathrm{mg} \pm 1 \cdot 4 ; \mathrm{F}_{1,27}=5 \cdot 74$, $P=0 \cdot 024)$ and larger hearts (non-parasitized: $130 \cdot 8 \mathrm{mg} \pm 1 \cdot 1$; parasitized: $164 \cdot 7 \mathrm{mg} \pm 1 \cdot 1 ; \mathrm{F}_{1,26}=$ 6.58, $P=0.016)$ than controls, but testes were of similar mass (non-parasitized: $121.0 \mathrm{mg} \pm 14 \cdot 8$; parasitized: $\left.78 \cdot 2 \mathrm{mg} \pm 12 \cdot 3 ; \mathrm{F}_{1,26}=0 \cdot 30, P=0 \cdot 59\right)$.

\section{DISCUSSION}

Our study demonstrates that flea infestation by Nosopsyllus fasciatus can reduce life span of one of its natural hosts, the common vole. Brown et al. (1995) also showed that survival was approximately $12 \%$ lower for cliff swallows Petrochelidon pyrrhonota reproducing in parasitized nests compared to those from fumigated nests, demonstrating that parasitism experienced during the short period of reproductive effort can result in loss of up to 1 year of life-time reproductive success. We found that the mean life span of parasitized voles decreased by $36 \%$, or 166 days. Theoretically, the life-time reproductive success is correlated with life span in iteroparous species because a long life span may be associated with a higher number of possible breeding attempts and more breeding experience (Clutton-Brock, 1988; Stearns, 1992; Weladji et al. 2006). This statement is confirmed by several empirical studies in rodents (Ribble, 1992; Wauters and Dhondt, 1995) as well as in small birds (Schmoll et al. 2009) and in large mammals (Pettorelli and Durant, 2007; Weladji et al.
2006). In the present study, voles had no access to mates and we have thus no data on life-time reproductive success. However, we can hypothesize that in natural conditions, the decrease of life span induced by parasites or other extrinsic mortality factors leads to a lower number of breeding opportunities and to a lower life-time reproductive success, especially for short-lived species exposed to high extrinsic mortality factors (Christe et al. 2006). Moreover, experimental evidence suggests that endoparasitism reduces the reproductive success of breeding common voles (Deter et al. 2007).

The exact mechanisms by which flea infestation accelerates death are not yet clear. Nevertheless, this experiment may provide us with some non-mutually exclusive hypotheses, suggesting that flea infestation can trigger complex trade-offs between different functions like the immune system, erythropoiesis and blood circulation. The immune system is chronically in demand and the observed huge spleen relative to the body mass of parasitized voles (on average $274 \%$ of the mass of the spleen of the control voles) can be due to intense immune activity (Møller et al. 1998) which might favour immune disorder and auto-immune diseases (Sorci and Faivre, 2009). Nevertheless, the immune effort by itself does not shorten the life span of common voles (Devevey et al. 2009). Moreover, rodents parasitized by fleas are immuno-depressed (Devevey et al. 2008; Goüy de Bellocq et al. 2006), and this makes them more sensitive to diseases. Alternatively, the spleen may also act as an erythropoietic organ in microtines (Watkins et al. 1991), and thus splenomegaly observed in this study could be due to a combined effect of immune activation and the necessity to produce new red blood cells. This could be one of the morphological changes induced by anaemia. Besides, the hypothesis that parasitized voles have a higher resting metabolic rate due to an increased breath and/or heart output in response to anaemia (Devevey et al. 2008) is now corroborated by the finding that parasitized voles have a heavier heart than control voles. The precocious anaemia associated with low body condition early in life and other physiological disorders may explain the early death of parasitized voles. In addition, fleas are known to be vectors of several microorganisms (Ricketssiae typhus, trypanosomes ...) (Medvedev and Krasnov, 2006) with potentially pathogenic effects on the host. The measured cost of flea infestation is thus the sum of the direct effects of the flea and the indirect consequences of potentially inoculated pathogens.

Overall, these results demonstrate that the presence of fleas affects one important host life-history trait in a way that could depress fitness. It emphasizes the necessity to integrate parasitism, even by seemingly inconspicuous fleas, in studies involving the life-history traits of small mammals. Macroparasites as well as microparasites can affect survival and life 
span (Burthe et al. 2008) and this may in turn affect population dynamics (Deter et al. 2008; Townsend et al. 2009).

All manipulations were done under control of the Vaud Veterinary Authorities, authorization 1848.

We are very grateful to J. Notari for his help with the experiment, and to K. S. Osmont, K. Harle, N. Kaldonski and N. Charbonnel for their insightful suggestions. We thank P. Bize and two anonymous referees who greatly helped to improve the manuscript. This research was supported by grants 3100A0-104118 and 3100A0-120479 from the Swiss National Science Foundation.

\section{REFERENCES}

Anderson, R. M. and May, R. M. (1978). Regulation and stability of host-parasite population interactions: I. Regulatory Processes. Fournal of Animal Ecology 47, 219-247.

Brisson, D., Dykhuizen, D. E. and Ostfeld, R. S. (2008). Conspicuous impacts of inconspicuous hosts on the Lyme disease epidemic. Proceedings of the Royal Society of London, B 275, 227-235.

Brown, C. R., Brown, M. B. and Rannala, B. (1995). Ectoparasites reduce long-term survival of their avian host. Proceedings of the Royal Society of London, B 262, 313-319.

Burthe, S., Telfer, S., Begon, M., Bennett, M., Smith, A. and Lambin, $\mathbf{X}$. (2008). Cowpox virus infection in natural field vole Microtus agrestis populations: significant negative impacts on survival. Fournal of Animal Ecology 77, 110-119.

Clutton-Brock, T. H. (1988). Reproductive Success. University of Chicago Press, Chicago, Il, USA.

Christe, P., Keller, L. and Roulin, A. (2006). The predation cost of being a male: implications for sex-specific rates of ageing. Oikos 114, 381-384.

Deter, J., Charbonnel, N., Cosson, J.-F. and Morand, S. (2008). Regulation of vole populations by the nematode Trichuris arvicolae: insights from modelling. European Fournal of Wildlife Research 54, 60-70.

Deter, J., Cosson, J.-F., Chaval, Y., Charbonnel, N. and Morand, S. (2007). The intestinal nematode Trichuris arvicolae affects the fecundity of its host, the common vole Microtus arvalis. Parasitological Research 101, 1161-1164.

Devevey, G., Chapuisat, M. and Christe, P. (2009). Longevity differs among sexes but is not affected by repeated immune activation in voles (Microtus arvalis). Biological Fournal of the Linnean Society 97, 328-333.

Devevey, G., Niculita-Hirzel, H., Biollaz, F., Yvon, C., Chapuisat, M. and Christe, P. (2008).

Developmental, metabolic and immunological cost of flea infestation in the common vole. Functional Ecology 22, 1091-1098.

Dobson, A. P. and Hudson, P. J. (1992). Regulation and stability of a free-living host-parasite system: Trichostrongylus tenuis in Red Grouse. II. Population Models. Fournal of Animal Ecology 61, 487-498.

Garcia, E. S., Ratcliffe, N. A., Whitten, M. M. A., Gonzalez, M. S. and Azambuja, P. (2007). Exploring the role of insect host factors in the dynamics of
Trypanosoma cruzi-Rhodnius prolixus interactions.

Fournal of Insect Physiology 53, 11-21.

Goüy de Bellocq, J., Krasnov, B. R., Khokhlova, I. S., Ghazaryan, L. and Pinshow, B. (2006).

Immunocompetence and flea parasitism of a desert rodent. Functional Ecology 20, 637-646.

Hawlena, H., Krasnov, B. R., Abramsky, Z., Khokhlova, I. S., Saltz, D., Kam, M., Tamir, A. and Degen, A. A. $(2006 a)$. Flea infestation and energy requirements of rodent hosts: are there general rules? Functional Ecology 20, 1028-1036.

Hawlena, H., Abramsky, Z. and Krasnov, B. R. $(2006 b)$. Ectoparasites and age-dependent survival in a desert rodent. Oecologia 148, 30-39.

Hudson, P. J., Dobson, A. P. and Newborn, D. (1998). Prevention of population cycles by parasite removal. Science 282, 2256-2258.

Hudson, P. J., Newborn, D. and Dobson, A. P. (1992). Regulation and stability of a free-living host-parasite system: Trichostrongylus tenuis in Red Grouse. I. Monitoring and parasite reduction experiments. Fournal of Animal Ecology 61, 477-486.

Jacob, J. (2003). Body weight dynamics of common voles in agro-ecosystems. Mammalia 67, 559-566.

Kaplan, E. L. and Meier, P. (1958). Nonparametric estimation from incomplete observations. Fournal of the American Statistical Association 53, 457-481.

Khokhlova, I. S., Krasnov, B. R., Kam, M., Burdelova, N. I. and Degen, A. A. (2002). Energy cost of ectoparasitism: the flea Xenopsylla ramesis on the desert gerbil Gerbillus dasyurus. Fournal of Zoology 258, 349-354.

Medvedev, S. G. and Krasnov, B. R. (2006). Fleas: permanent satellites of small mammals. In Micromammals and Macroparasites. From Evolutionary Ecology to Management (ed. Morand, S., Krasnov, B. R. and Poulin, R.), pp. 161-177. Springer-Verlag, Tokyo, Japan.

Møller, A. P. (1997). Parasitism and the evolution of host life history. In Host-Parasite Evolution, General Principles and Avian Models (ed. Clayton, D. H. and Moore, J.), pp. 105-127. Oxford University Press, New York, USA

Møller, A. P., Christe, P., Erritzoe, J. and Mavarez, J. (1998). Disease and immune defence. Oikos 83, 301-306.

Neuhaus, P. (2003). Parasite removal and its impact on litter size and body condition in Columbian ground squirrels (Spermophilus columbianus). Proceedings of the Royal Society of London, B 270, S213-S215.

Petorelli, N. and Durant, S. M. (2007). Longevity in cheetahs: the key to success? Oikos 116, 1876-1886.

Pipano, E. (2003). Recent developments in the control of ectoparasites and endoparasites of dogs and cats with selamectin. Israel Fournal of Veterinary Medicine 58, 2-3.

Ribble, D. O. (1992). Lifetime reproductive success and its correlates in the monogamous rodent Peromyscus californicus. Fournal of Animal Ecology 61, 457-468.

Saino, N., Calza, S. and Møller, A. P. (1998). Effects of a dipteran ectoparasite on immune response and growth trade-offs in barn swallow, Hirundo rustica, nestlings. Oikos 81, 217-228.

Schmoll, T., Schurr, F. M., Winkel, W., Epplen, J. T. and Lubjuhn, T. (2009). Lifespan, lifetime reproductive performance and extra-pair paternity loss 
of within-pair and extra-pair offspring in the coal tit Periparus ater. Proceedings of the Royal Society of London, B 276, 337-345.

Sorci, G, and Faivre, B. (2009). Inflammation and oxidative stress in vertebrate host-parasite systems. Philosophical Transactions of the Royal Society 364, 71-83.

Stearns, S. C. (1992). The Evolution of Life Histories. Oxford University Press, Oxford, UK.

Townsend, S. E., Newey, S., Thirgood, S. J., Matthews, L. and Haydon, D. T. (2009). Can parasites drive population cycles in mountain hares? Proceedings of the Royal Society of London, B 276, 1611-1617.

van de Pol, M. and Verhulst, S. (2006). Age-dependent traits: a new statistical model to separate within- and between-individual effects. American Naturalist 167, 766-773.

Watkins, R. A., Moshier, S. E., O'dell, W. D. and Pinter, A. J. (1991). Splenomegaly and reticulocytosis caused by Babesia microti infections in natural populations of the Montane Vole, Microtus montanus. Fournal of Protozoology 38, 573-576.

Wauters, L. A. and Dhondt, A. A. (1995). Lifetime reprodiuctive success and its correlates in female eurasian red squirrels. Oikos 72, 402-410.

Weladji, R. B., Gaillard, J.-M., Yoccoz, N. G., Holand, O., Mysterud, A., Loison, A., Nieminen, M. and Stenseth, N. C. (2006). Good reindeer mothers live longer and become better in raising offspring. Proceedings of the Royal Society of London, B 273, 1239-1244. 